\title{
O deserto verde cresce em Alagoas: uma análise crítica da expansão do eucalipto no estado
}

The green desert grows in Alagoas: a critical analysis of eucalyptus expansion in the state

\author{
Lucas Gama Lima \\ Professor Adjunto da Universidade Federal de Alagoas, \\ Campus do Sertão, Brasil \\ lucasaelima@yahoo.com.br \\ Jéssica Lima Barbosa \\ Graduanda em Geografia (Licenciatura) - Participante do \\ Observatório de Estudos sobre a Luta por Terra e Território, \\ vinculada ao Grupo de Estudos e Pesquisas em Análise Regional (GEPAR), Brasil \\ jeslima92@gmail.com \\ José Rodolfo da Silva Santos \\ Graduando em Geografia (Licenciatura) - Participante do \\ Observatório de Estudos sobre a Luta por Terra e Território, vinculada ao Grupo de Estudos e \\ Pesquisas em Análise Regional (GEPAR), Brasil \\ rodolfo.rodolfosantos@outlook.com.br \\ Eduardo Neório Lima \\ Graduando em Geografia (Licenciatura) - Participante do \\ Observatório de Estudos sobre a Luta por Terra e Território, vinculada ao Grupo de Estudos e \\ Pesquisas em Análise Regional (GEPAR), Brasil \\ eduardo sk8123@hotmail.com
}

\section{Resumo}

Na última década, a superfície cultivada com eucalipto em Alagoas cresceu exponencialmente. A territorialização do eucalipto em Alagoas ocupa extensas áreas da Mesorregião Leste e Agreste e tem o objetivo de fomentar o complexo de madeira-papel-celulose, apropriando-se de condições vantajosas para a reprodução ampliada do capital. Contraditoriamente, o aumento da superfície cultivada com eucalipto no estado coincide com a diminuição da oferta de um importante gênero, como o feijão, fragilizando a soberania alimentar. Ademais, a territorialização do eucalipto apresenta seus primeiros sinais de destruição social e ambiental, a exemplo da diminuição da oferta hídrica e contaminação de plantações e corpos d'agua de comunidades. Compreende-se que o advento do agronegócio do eucalipto, longe de representar uma alteração da realidade hegemônica do estado, atualiza suas contradições por meio do deserto verde.

Palavras-chave: Eucalipto, capital, agronegócio.

\begin{abstract}
In the last decade, the area under cultivation of eucalyptus in Alagoas has grown exponentially. The territorialization of eucalyptus in Alagoas occupies broad areas of the east and wild mesoregions, and its objective is to promote the complex of wood, paper, and pulp, appropriating advantageous conditions for the increased production of capital. Contradictorily, the increase of cultivated area with eucalyptus in the state coincides with the decrease in the supply of a vital foodstuff, such as beans, undermining the food sovereignty. Furthermore, the territorialization of eucalyptus presents its first signs of social and environmental destruction; for instance, the decrease in the water supply
\end{abstract}


and the contamination of plantations and water bodies of communities. It is understandable that the advent of agribusiness of eucalyptus, far from providing an amendment of the hegemonic reality of the state, renews its contradictions through the green desert.

Keywords: Eucalyptus, capital, agribusiness.

\section{INTRODUÇÃO}

A economia de Alagoas esteve ancorada, durante séculos no monocultivo da cana-deaçúcar, que assegurou a reprodução da estrutura fundiária concentrada e do poder político oligárquico no estado. Entretanto, a crise que se abate sobre o setor sucroalcooleiro alagoano tem resultado numa transição agrícola com forte promoção do Estado. Grupos empresariais, tradicionalmente vinculados à cana-de-açúcar, estão reservando parte notável de hectares de suas propriedades ao cultivo de eucalipto. A narrativa, fartamente veiculada pelo Estado e pelos grupos empresariais envolvidos, baseia-se numa suposta alternativa econômica ao cultivo da gramínea, com a promessa de geração de empregos e de respeito ao meio-ambiente.

É propositalmente ocultado dessa narrativa o fato do monocultivo do eucalipto estar imerso, tal como o da cana-de-açúcar, no modus operandi do agronegócio, que preserva a grande propriedade, restringe a produção de alimentos em nome da produção de commodities, atrofia a oferta de empregos e destrói, constantemente, a natureza com o generalizado uso de agrotóxicos e fertilizantes derivados do petróleo.

O artigo analisa a expansão do eucalipto em Alagoas, como parte do complexo de madeirapapel-celulose, que continua a se expandir no Brasil e que representa uma das destacadas dimensões do agronegócio. Parte-se do pressuposto de que a territorialização do eucalipto no estado visa à reprodução ampliada do capital, guiada por condições edafoclimáticas que catapultem a diminuição da rotação do capital e por generosos incentivos fiscais advindos do Estado.

As linhas que seguem estão divididas em dois momentos. No primeiro, é feita uma breve abordagem da crescente expansão da produção do eucalipto e de seus derivados no Brasil, situando os fundamentos em que se assentam esse fenômeno. No segundo, é examinado o recente desembarque do eucalipto em Alagoas, identificando seu vertiginoso crescimento, o apoio do Estado, além dos primeiros desdobramentos sociais e ambientais, que denotam o deserto verde.

Para subsidiar a discussão teórica, serão usados diversos autores da Geografia e de outros ramos das Ciências Humanas, a exemplo de Almeida (2012); Lessa (2013); Binkowaki (2014); Oliveira e Santos (2016); Perpetua e Thomaz Junior (2016) e Porto-Gonçalves (2016). Também serão apreciados dados e informações do IBGE (2017), da Conab (2018), do DIEESE (2014), Governo de Alagoas (2015a; 2015b; 2017) e publicações oriundas do setor empresarial, a saber: IBÁ (2017; 2018) e Senai (2018). 
A análise reflexiva baseia-se no materialismo histórico-dialético, que perscruta as contradições do fenômeno, inserindo-o como parte de uma totalidade hegemônica. A categoria território será usada como referência para a compreensão da territorialização do agronegócio do eucalipto em Alagoas. Consoante Oliveira (2004), o território sob o capitalismo é uma unidade dialética e contraditória assentada na valorização, produção e reprodução do capital. Nesse sentido, a territorialização é a instalação do capitalista/proprietário da terra que ambiciona, simultaneamente, o lucro e a renda da terra.

\section{O AGRONEGÓCIO DO EUCALIPTO NO BRASIL}

O cultivo de eucalipto no Brasil, como uma das importantes engrenagens do complexo de madeira-papel-celulose, tem se expandido nas últimas décadas. Existem hoje no país 7,84 milhões de hectares de árvores plantadas para fins comerciais, sendo que 5,67 milhões desses hectares são de eucaliptos. Este gênero arbóreo, endêmico da Austrália, foi introduzido no país, em meados do século XIX, e teve seu cultivo galvanizado durante a ditadura empresarial-militar, através do Programa de Incentivos Fiscais para o Reflorestamento (Lei no 5106 de 1966), que foi responsável pelo plantio de 3,5 milhões de extratos arbóreos com fins comerciais.

Mais recentemente, a partir da década de 1990, o apoio do Estado ao complexo de madeira-papel-celulose permitiu a concessão de crédito e de incentivos fiscais para a expansão do plantio de eucaliptos e o fortalecimento de corporações industriais especializadas na produção de papel, celulose, móveis e biocombustíveis. A territorialização dos eucaliptos concentrou-se, majoritariamente, nos estados de Minas Gerais (24\%), São Paulo (17\%), Mato Grosso do Sul (15\%) e Bahia (11\%), mas fez de quase todo o território brasileiro um imenso lócus espacial para o cultivo e exportação desse gênero arbóreo e de seus derivados. Nas Figuras 1 e 2 consta a evolução da produção e da exportação de celulose pelo Brasil. Na Figura 1, não obstante a pequena diminuição e estagnação da produção de celulose, entre os anos de 2011 e 2012, há um contínuo crescimento desde 2013, alcançando a marca recorde de 19.492 toneladas produzidas. Na Figura 2, a exportação de celulose segue um padrão de crescimento constante nos últimos 10 anos, atingindo o patamar recorde de 13.200 milhões de toneladas em 2017. Tamanha expressividade fez do Brasil o segundo maior produtor de celulose do mundo, atrás, apenas, dos Estados Unidos e à frente de países de clima temperado, tradicionalmente produtores da pasta da madeira, a exemplo do Canadá, da Suécia, da Finlândia e do Japão (IBÁ, 2017). Os principais destinos da celulose exportada pelo Brasil estão, disparadamente, na China, de onde provêm mais de $40 \%$ do volume de dólares auferidos, e a Europa, por sua vez, responsável por mais de 30\% dos dólares (IBÁ, 2018). 


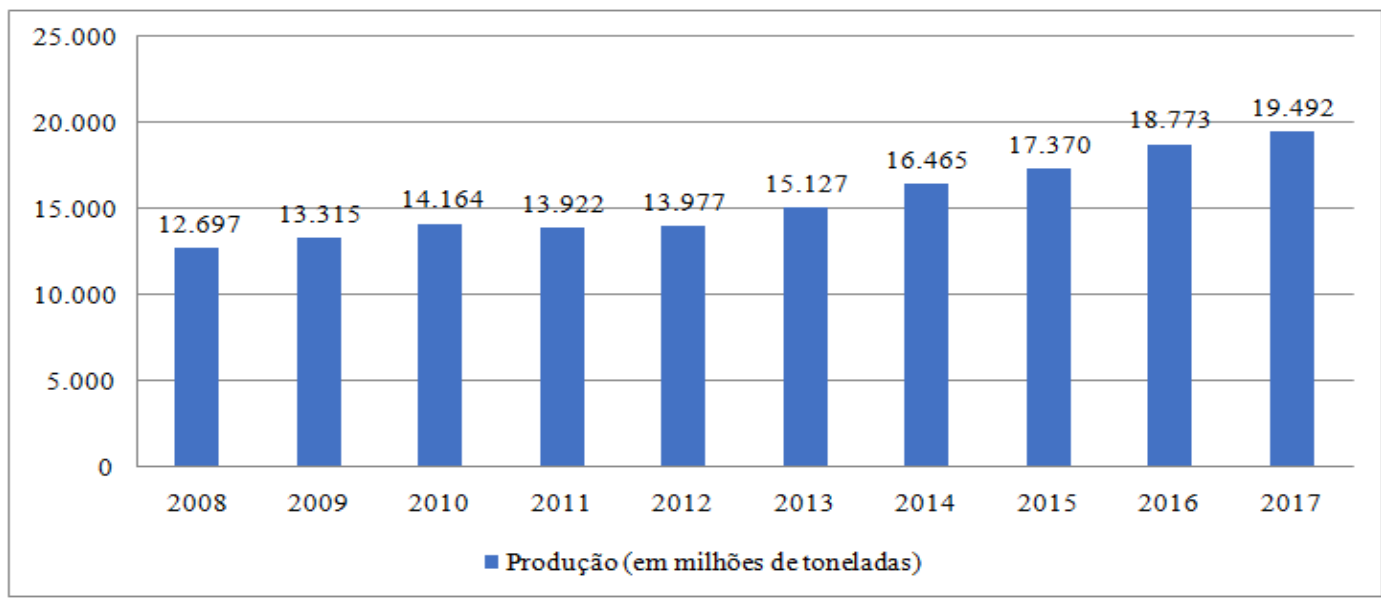

Figura 1 - Produção de celulose pelo Brasil.

Fonte: IBÁ, 2018. Elaboração: própria.

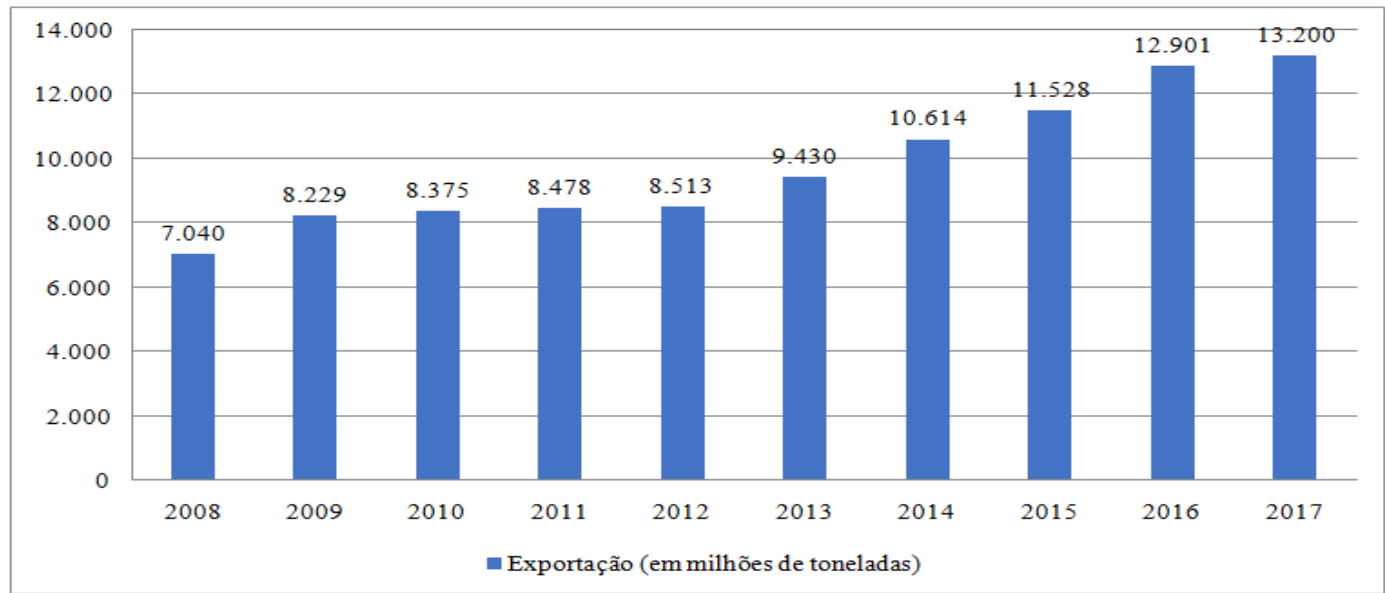

Figura 2 - Exportação de celulose pelo Brasil.

Fonte: IBÁ, 2018. Elaboração: própria.

O boom do cultivo de eucalipto no país está, indissociavelmente, relacionado à possibilidade de reprodução ampliada do capital. Oliveira e Santos (2016) explicam que várias empresas transnacionais adentraram ao país motivados pelas singulares condições edafoclimáticas, que possibilitam uma velocidade de produção de biomassa até cinco vezes superior às encontradas em países de clima temperado. A extraordinária velocidade com que o eucalipto cresce em terras tropicais constitui um elemento importante para entender a territorialização das corporações, uma vez que a celeridade da rotação do capital (intervalo entre o plantio e a colheita) enseja o alcance mais rápido dos lucros. Acrescenta-se a isso, o baixo preço das terras no Brasil e, não menos importante, a disponibilidade de um grandioso exército de reserva de força-de-trabalho, sempre sujeito a superexploração promovida pelo capital.

A respeito da velocidade de crescimento do eucalipto, relatório divulgado pelo IBÁ (2017) aponta que o tempo médio de rotação no Brasil é de 5 a 7 anos, enquanto que, nos Estados Unidos, esse tempo é de mais de 20 anos e, em zonas de altas latitudes, como o Canadá e os países da Escandinávia, ultrapassa os 30 anos. O clima tropical, encontrado no Brasil, também permite uma 
biomassa maior. A produtividade média no país atingiu a marca de $35 \mathrm{~m}^{3} / \mathrm{ha} /$ ano contra 10 $\mathrm{m}^{3} /$ ha/ano nos Estados Unidos, pouco mais de $5 \mathrm{~m}^{3} /$ ha/ano nos países da Escandinávia e menos de 5 $\mathrm{m}^{3} / \mathrm{ha} /$ ano no Canadá.

Segundo Almeida (2012), o advento do ingresso de corporações transnacionais do complexo de madeira-papel-celulose também tem a ver com o legado de destruição ambiental em países do Norte temperado. Lá, “fábricas de celulose são mal vistas por seus graves impactos ambientais e, portanto, as empresas de lá têm transferido suas fábricas para países como o Brasil” (Ibid, p. 6; 7).

Trata-se de uma ação orquestrada pelas corporações transnacionais desse ramo que transferem para outros países o ônus ambiental e social decorrente da exploração dessa commodity. Em países periféricos como o Brasil, a narrativa de uma suposta economia verde costuma ressoar com mais facilidade, veiculada pelo Estado e pela intensa campanha midiática, que apela para a ideia de compromisso ambiental.

A insistente associação entre cultivo comercial de árvores plantadas, a exemplo do eucalipto, e o reflorestamento, como se fossem sinônimos, é uma das artimanhas discursivas que almejam conferir legitimidade à expansão de um empreendimento destruidor. Esconde que "eucalipto e floresta, apesar de algumas semelhanças, são diferentes, tanto em sua constituição como função" (LIMA et al., 2016, p. 29). Uma floresta pressupõe uma complexa diversidade da flora e da fauna, riqueza que está em desalinho com a uniformidade simplificadora da monocultura dos eucaliptos.

\footnotetext{
Defender a "aptidão" para o plantio "florestal" enquanto sinônimo de monocultivo de eucalipto é uma das formas de naturalizar política, econômica e socialmente os processos de implantação e expansão dos monocultivos. As justificativas para a implantação e manutenção dos grandes projetos são construídas e defendidas com arcabouços teóricos, jurídicos, políticos e sociais. Aquilo que na essência é uma necessidade do capital - a acumulação e reprodução capitalista - aparece como necessidade da sociedade (LIMA et al., 2016, p. 24).
}

Almeida (2012) afirma que a economia verde se constitui como uma ideologia, arvorandose como a solução para a crise climática e ambiental, por plantar árvores que podem fixar carbono, a despeito de outros desdobramentos nefastos à natureza, mas, meticulosamente, obnubilados, a exemplo da pulverização de agrotóxicos e fertilizantes químicos. Esse mercado de carbono é uma "clara jogada de marketing para pintar de verde um processo ecológico e socialmente predatório" (SILVA; PORTO-GONÇALVES, 2006, p. 3).

[...] os maiores infratores da indústria podem "contrabalancear" seus danos em outros lugares (financiando programas de reflorestamento, por exemplo), em vez de reduzi-los diretamente (WALLIS, 2012, p. 26). 
A respeito desses perversos desdobramentos à natureza, Kudlavicz (2011) é enfático ao afirmar que o agronegócio do eucalipto pressupõe a introdução de pacotes tecnológicos (mecanização, adubos químicos e agrotóxicos) que acarretam perda da biodiversidade, degradação dos solos, poluição e esgotamento dos rios, lagos e aquíferos. Ademais, também são responsáveis pela redução da oferta de empregos, impactos na soberania alimentar e piora nas condições de vida das populações sob o cerco dessas plantações.

Em uma investigação sobre os efeitos da territorialização do eucalipto no norte de Minas Gerais, Brito (2017) sublinha que ao mesmo podem ser imputadas diversas acusações de destruição ambiental, a exemplo de entupimento de nascentes, secamento de rios, além de conflitos com os camponeses da região. Estes que, há séculos, já habitavam a área, não foram consultados.

Situação similar é apontada por Eskinazi e Souza (2013), em investigação realizada sobre a presença da monocultura do eucalipto no Vale do Paraíba paulista, através da qual se verificou uma mudança substancial nos regimes do ciclo hidrológico, acarretando em seca de córregos e poços. Adicionalmente, o uso massivo de agrotóxicos provocou a morte de animais, o adoecimento de agricultores, contaminação dos corpos d'água e perda da biodiversidade da fauna e da flora.

E não se trata de uma particularidade do eucalipto no Brasil, Binkowaki (2014) afirma se tratar de uma lógica global e que tem acometido os neófitos produtores comerciais de monocultivos de árvores plantadas. Ela menciona o caso da Indonésia, indicando que os efeitos neste país asiático perpassam por poluição de fontes de água, perda de biodiversidade local e deslocamento forçado de populações.

Em face desse indesejado legado, não é uma afirmação randômica nomear o monocultivo comercial do eucalipto como um deserto verde, pois, sob a aparência de uma rica floresta, escondem-se maiúsculas contradições. Observemos o contexto da expansão do eucalipto em Alagoas.

\section{A EXPANSÃO DO EUCALIPTO EM ALAGOAS}

A economia alagoana está ancorada no monocultivo da cana-de-açúcar, ocupando extensas terras da Mesorregião Leste e de parte do Agreste, as quais possuem solos profundos, com boa drenagem e relativamente próximas a fontes de água. Na formação territorial desse estado, o cultivo da cana-de-açúcar serviu de base para que famílias oligárquicas, associadas ou não a outros grupos empresariais, apropriassem monopolicamente as terras férteis.

A cultura da cana-de-açúcar [...] assume aspectos de monocultura que, pela sua própria natureza, exige terras férteis, úmidas, e só é economicamente viável quando cultivada em grandes extensões; por isso mesmo, contribui para a consolidação do elevado padrão de concentração da posse da terra, que, por sua vez, gerou na sociedade alagoana uma grande desigualdade produtiva e distributiva (LIRA, 1997, p. 39). 
Tão longevo controle sobre as terras e sobre o plantio da referida gramínea somente foi possível em razão do suporte do Estado, o qual ofereceu toda sorte de incentivos, através de programas que, fatalmente, descambaram para a renúncia fiscal ou para generosos dispêndios de recursos públicos, vide o Instituto do Açúcar e do Álcool (IAA), o Programa Nacional de Melhoramento da Cana-de-Açúcar (Planalsucar), o Programa Nacional do Álcool (Proálcool) e, em âmbito estadual, o Banco do Estado de Alagoas (Produban). Acerca deste último, Carvalho (2009) sublinha que o mesmo acumulou um grande passivo, resultante da inadimplência do setor sucroalcooleiro, sendo este o principal responsável pela grave crise econômica que se abateu sobre o Estado.

O fim de mais um ciclo de graciosas concessões oferecidas pelo Estado ao setor sucroalcooleiro ensejou uma reestruturação produtiva, a partir da década de 1990, que culminou, de acordo com Silva (2013), na redução da superfície plantada, na incorporação de tecnologias, na falência de várias usinas, na mobilidade espacial do capital para outros estados do país e no aumento das massas de desempregados. "A classe trabalhadora rural do setor, que já era relativamente pequena e sazonal, diminuiu ainda mais de tamanho e teve suas condições de vida pioradas, já que a diminuição dos postos de trabalho pressionou os salários para baixo" (Ibid, p. 95; 96).

A reestruturação produtiva por que passou o setor sucroalcooleiro alagoano, embora tenha elevado sua produtividade (ton/ha), não se mostrou capaz de torná-lo suficientemente competitivo frente ao mercado nacional e sem os vultosos subsídios do Estado. Ao fixarmos o olhar sobre os dados mais recentes do setor, nas Figuras 3 e 4, é possível notar que desde o biênio 2012/13 a área cultivada com cana-de-açúcar vem decrescendo, tendo alcançado no biênio 2018/19 a menor área em pouco mais de uma década, a saber, 293,2 mil hectares, ou seja, uma redução de quase 140 mil hectares. O volume de produção, desde o biênio 2011/12 apresenta uma tendência decrescente, excetuando o biênio 2018/19 cujo valor auferido é superior aos três biênios anteriores. Em que pese o registro de crescimento no biênio 2018/19, as toneladas de cana-de-açúcar estão bem abaixo do volume produzido em pouco mais de uma década, a saber: 9.199 toneladas a menos.

É necessário mencionar que a histórica apropriação monopólica das melhores terras pelo setor sucroalcooleiro impediu que as mesmas fossem destinadas ao cultivo de alimentos, ocasionado sérias fragilidades à soberania alimentar de Alagoas, haja vista que parte dos itens alimentares de consumo ordinário da população é proveniente de outros estados. Lessa (2013, p. 318) expõe que "há décadas Alagoas não consegue produzir todos os alimentos necessários para a sua crescente população urbana, obrigando-se a importar vários dos agropecuários consumidos no estado". Tal situação encarece o preço dos alimentos, obstaculizando o acesso regular da população aos mesmos. 


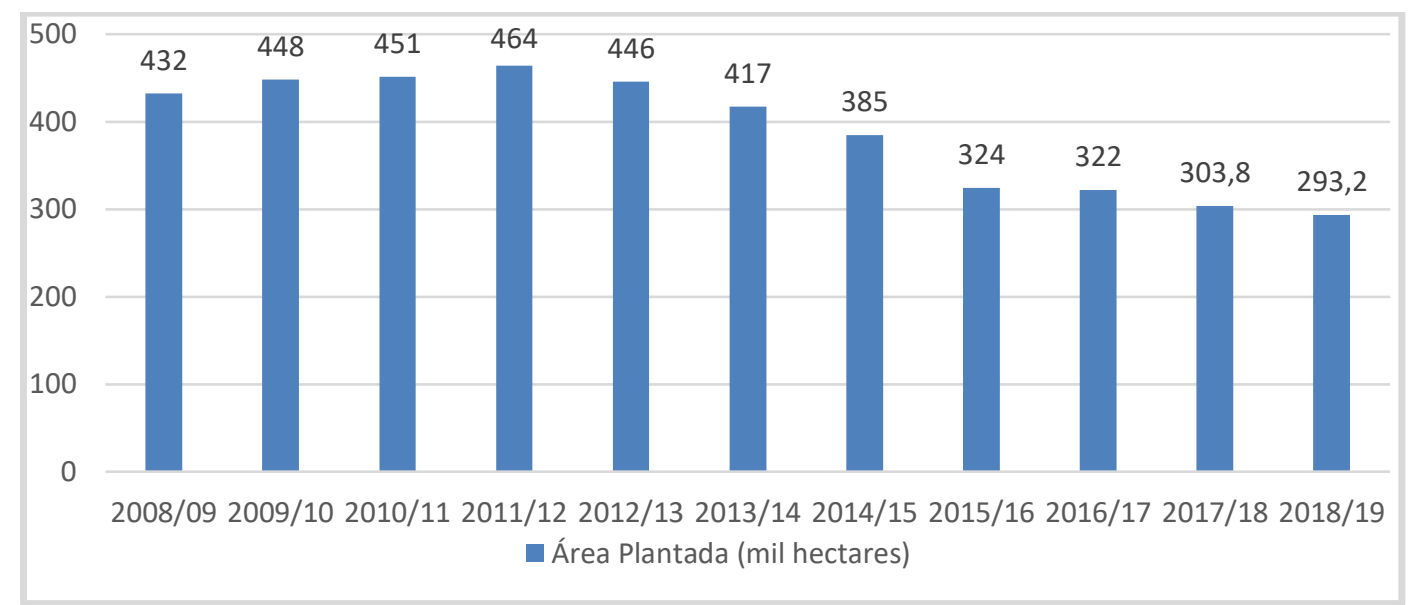

Figura 3 - Superfície cultivada com cana-de-açúcar em Alagoas (em mil hectares).

Fonte: Conab, 2019. Elaboração: própria.

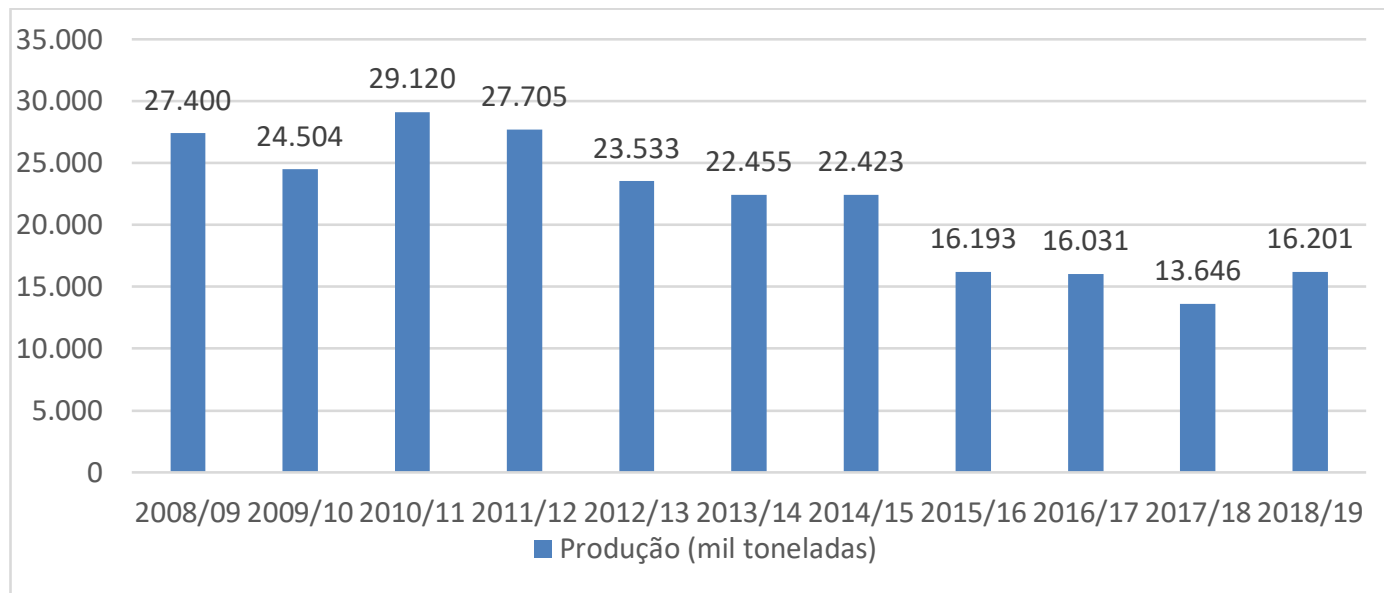

Figura 4 - Produção de cana-de-açúcar em Alagoas (em mil toneladas).

Fonte: Conab, 2019. Elaboração: própria.

Os últimos dados da Pesquisa de Orçamentos Familiares (POF-IBGE), referente ao período de 2008/2009, apontavam que mais de 60\% das famílias entrevistadas em Alagoas manifestavam insatisfação com a quantidade de alimentos consumida, alegando ser insuficiente. A referida proporção elevada fez de Alagoas o estado com o mais expressivo percentual de famílias não satisfeitas com o seu consumo de alimentos no Brasil. Seguramente, o quadro tem relação direta com a estrutura fundiária concentrada no estado e que monopoliza terras para o setor sucroalcooleiro em detrimento da oferta de alimentos.

O alagoano é, portanto, um trabalhador particularmente subalimentado, sua força de trabalho é reproduzida em condições precárias, com uma quantidade de calorias e nutrientes abaixo daquela necessária para uma reprodução normal. Essa circunstância trágica é determinada por uma renda insuficiente para a satisfação das necessidades gerais mínimas do trabalhador [...] e pela oferta deficiente de alimentos (LESSA, 2013, p. 319; 321).

Vale lembrar que a mais recente diminuição da superfície cultivada com cana-de-açúcar, mencionada alhures, não resultou no aumento da oferta de alimentos no estado. Pelo contrário, ao observarmos os dados fornecidos pela Conab (2018), presentes às Figuras 5 e 6, nota-se que a área 
plantada e o volume de produção de feijão, item sumamente importante do cardápio alimentar da população de Alagoas, foram impactados com perdas. A superfície cultivada com feijão diminuiu, em pouco mais de uma década, de 83,5 mil hectares, no biênio 2008/09, para 43,4 mil hectares no biênio 2018/19. O volume da produção da leguminosa também foi reduzido, saindo de 38,4 mil toneladas, no biênio 2008/09, para 24,4 mil toneladas, no biênio 2018/19.

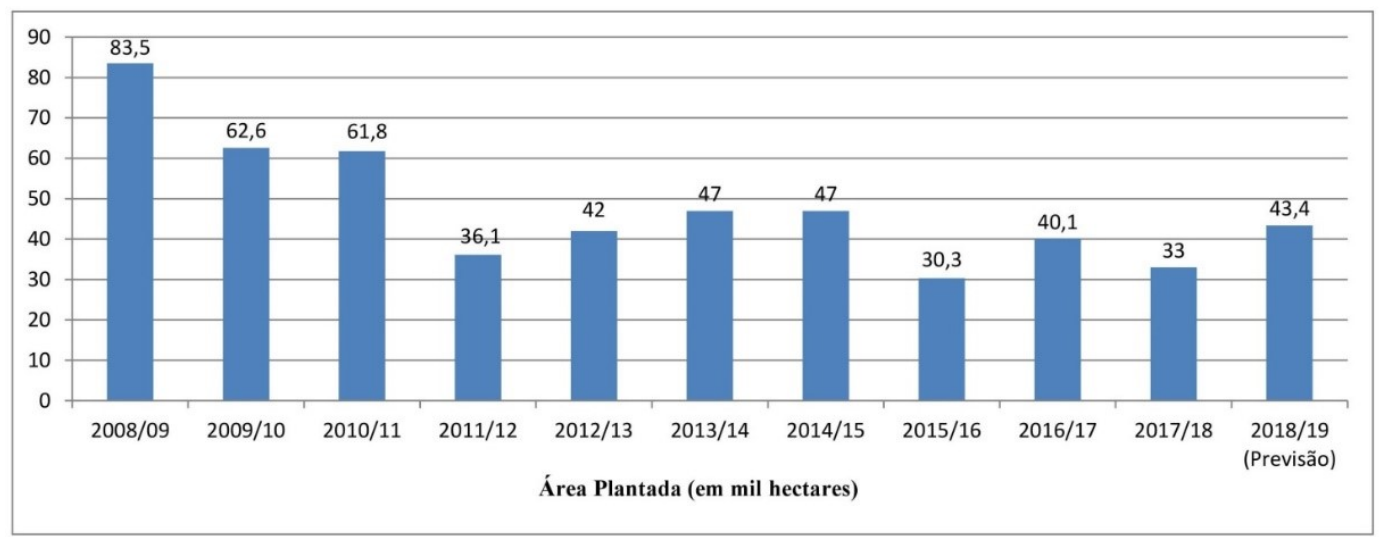

Figura 5 - Superfície cultivada com feijão em Alagoas (em mil hectares). Fonte: Conab, 2019. Elaboração: própria.

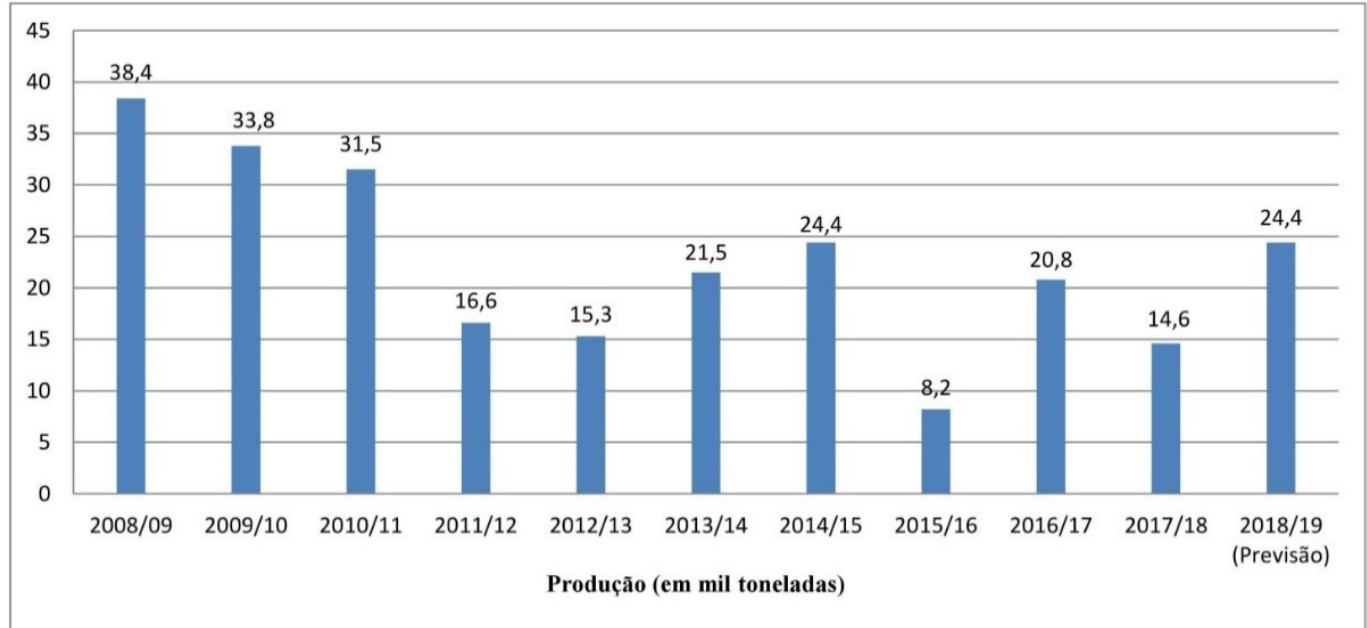

Figura 6 - Produção de feijão em Alagoas (em mil toneladas). Fonte: Conab, 2019. Elaboração: própria.

Os dados são elucidativos, pois - ao revelar que concomitante à redução da superfície e do volume de cana-de-açúcar ocorreu, também, a redução da oferta de um item da cesta básica alimentar do estado, como o feijão - escancara a perversidade da concentração da terra em Alagoas. O monopólio da terra obstaculiza o uso da propriedade fundiária para a produção de alimentos, mesmo quando se registra a diminuição da oferta e da superfície plantada com cana-de-açúcar. É uma flagrante constatação de que a propriedade fundiária no estado, sob o domínio do agronegócio sucroalcooleiro, é retida a seu bel-prazer, a despeito das graves consequências à soberania alimentar. 
Não obstante esse quadro trágico da estrutura fundiária de Alagoas, que compromete a oferta satisfatória de alimentos à população, o Estado tem incentivado aos grupos empresariais, monopolizadores da terra no estado, a diversificarem seus investimentos através de um novo empreendimento monocultor, a saber: o agronegócio do eucalipto. A proposta não objetiva substituir toda a plantação de cana-de-açúcar encontrada no estado pelo eucalipto, mas assegurar aos grupos empresariais a oportunidade de adentrarem em um ramo do agronegócio, em franco crescimento, e aureolado pela promessa de confiáveis lucros.

Em Alagoas está havendo uma forte adesão ao plantio de eucalipto por indústrias açucareiras, cerâmicas e por fornecedores de cana, especialmente os que desejam substituir seus canaviais em áreas de encostas os quais exigem um alto custo financeiro para a sua implantação e colheita, tornando-se, hoje, inviáveis (ANGEIRAS, 2017, p. 5).

A narrativa oficial do Estado para justificar o apoio à expansão do plantio de eucalipto em Alagoas e conquistar a legitimidade da iniciativa está pautada em quatro assertivas: a primeira é a assertiva econômica, que aventa a possibilidade de transição parcial do cultivo da cana-de-açúcar, dando ênfase à substituição da gramínea nos terrenos de topografia acidentada; a segunda envolve a questão de um suposto respeito ao meio ambiente, por diminuir a pressão sobre a floresta nativa e por fornecer energia limpa e renovável; a terceira é a sugestão de plantio junto à agricultura e à pecuária, numa sistema conhecido como agrosilvopastoril, que, pelo menos no papel, permitiria a participação de pequenos proprietários e; a quarta se trata de um possível aumento na geração de empregos.

A viabilização da cultura tem passado por testes de desempenho de clones e pelo emprego de práticas de manejo que possibilitam o máximo rendimento de biomassa. Nesse sentido, o Governo do Estado tem adotado estratégias em conjunto com empresas interessadas nesse ramo de atividade, dentre elas a proposta de implantação de termelétricas alimentadas por biomassa (ALAGOAS, 2015a, p. 20).

[...] o eucalipto torna-se ainda uma alternativa viável para o pequeno produtor rural, inclusive do Programa da Agricultura Familiar, que é incentivado pelo governo federal, uma vez que permite o seu consórcio com lavouras de subsistência ou outras determinadas lavouras e com a criação de gado (ALAGOAS, 2015b, p. 116).

Para atrair a atenção do capital, o Estado tem se empenhado em propagandear um cenário de extraordinária vantagem. Um dos elementos, usualmente, disseminados é que a produtividade média do eucalipto plantado em Alagoas é superior à produtividade média do Brasil. Segundo informação do Atlas de Bioenergia de Alagoas (2015a), uma publicação conjunta do Governo do Estado e da Universidade Federal de Alagoas (UFAL), a produtividade média no estado é de 45 a $50 \mathrm{~m}^{3} / \mathrm{ha} / \mathrm{ano}$, enquanto que no Brasil se obtém até $40 \mathrm{~m}^{3} / \mathrm{ha} / \mathrm{ano}$. Um outro elemento foi a ampliação da renúncia fiscal do Estado, mediante a reformulação do Programa de Desenvolvimento Integrado (Prodesin), que concede às indústrias isenção de até $92 \%$ do Imposto sobre Circulação de 
Mercadorias e Serviços (ICMS), para qualquer região do território alagoano e, adicionalmente, incentivo locacional, através da doação de terreno público para instalação.

A exortação empreendida pelo Estado para a territorialização do agronegócio do eucalipto em Alagoas começa promover o desembarque de grandes corporações do ramo no estado. A empresa Duratex Florestal S.A., uma empresa de capital aberto, com ações negociadas na Bolsa de Valores de São Paulo e controlada pela Itaúsa - uma holding que controla, além da Duratex, o Banco Itaú, a Alpargatas, o Itautec, dentre outros investimentos - já é proprietária de mais de 6 mil hectares de eucalipto em Alagoas por meio de uma joint venture com a Usina Caeté, que deu origem a Caetex Florestal S.A. (GAZETA DE ALAGOAS, 2014; VALOR MERCADO, 2017). A instalação da Duratex no estado contou com o apoio do Prodesin e promete formar um destacado polo moveleiro com a oferta de 460 empregos diretos (Alagoas, 2017).

De acordo com Angeiras (2017) e Senai (2018) houve um vertiginoso crescimento da superfície cultivada com eucalipto no estado, no período de 2008 à 2017, conforme representado na Figura 7. Chama atenção o ano de 2013, quando se superou, de forma inédita, a marca de mais de 2 mil hectares plantados em Alagoas, representando um crescimento de mais $1.200 \%$ em relação ao ano anterior. Ao total, o estado passou a abrigar uma superfície cultivada de, aproximadamente, 14 mil hectares. Vale registrar, entretanto, que esse valor total está em desacordo com o IBGE (2017) que, por meio de levantamento elaborado pela Produção da Extração Vegetal e da Silvicultura (PEVS), afirma existir 15.630 hectares cultivados com eucaliptos em Alagoas.

De igual modo, o IBGE (2017) aponta Alagoas como o $4^{\circ}$ estado do Nordeste em superfície cultivada com eucalipto, atrás da Bahia (571.241 ha), do Maranhão (236.480 ha) e do Piauí (37.761 ha) - estados que integram o famigerado polígono do agronegócio, conhecido como MATOPIBA - e bem acima de Sergipe, $5^{\circ}$ colocado, com 3.580 ha.

A Figura 8 ilustra a territorialização do eucalipto em Alagoas. É notória a sobreposição do monocultivo desse gênero arbóreo na Mesorregião Leste, área tradicionalmente destinada ao cultivo da cana-de-açúcar. Destaca-se a presença do cultivo do eucalipto na Mesorregião Agreste, inclusive, em Arapiraca, município que integra o perímetro do Semiárido de Alagoas. De acordo com estudo realizado pelo Senai (2018), os cinco municípios onde estão mais concentrados os cultivos são: Maceió (8.380 ha); Atalaia (2095 ha); Capela (509 ha); Viçosa (400 ha) e; Paripueira (380 ha). Os dados, portanto, confirmam a tendência de substituição parcial da commodity da canade-açúcar pela commodity do eucalipto. 


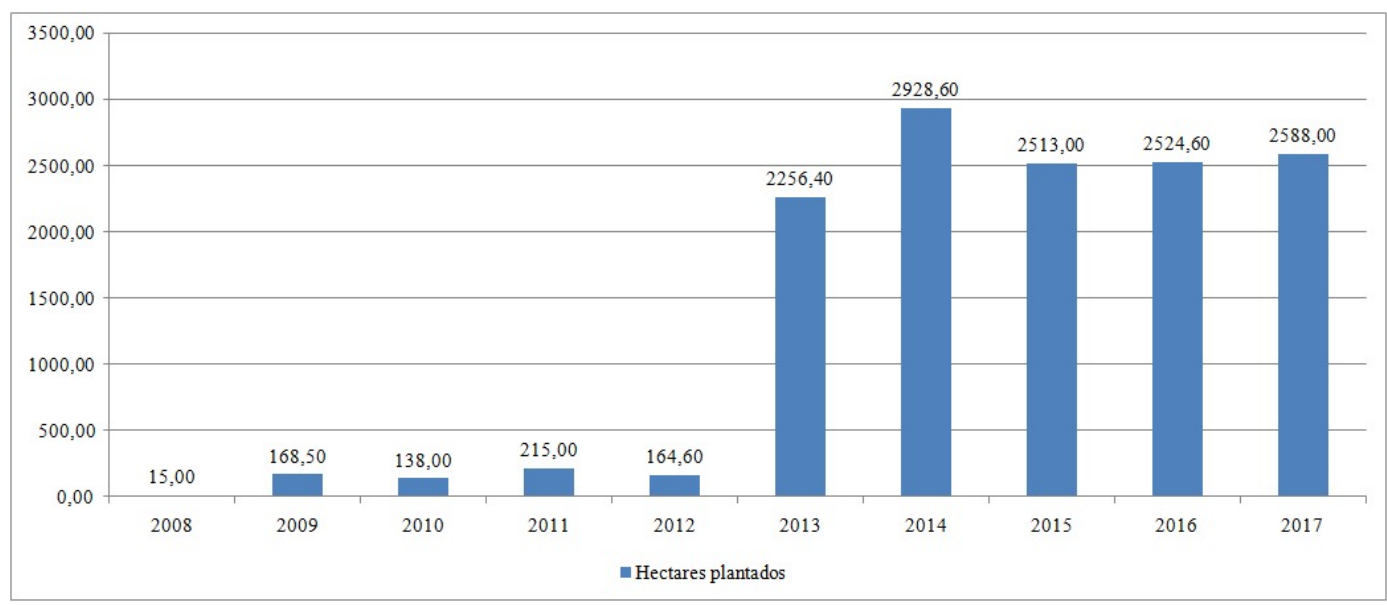

Figura 7 - Evolução da superfície cultivada com eucaliptos em Alagoas (em ha).

Fonte: Angeiras (2017); Senai (2018). Elaboração: própria.

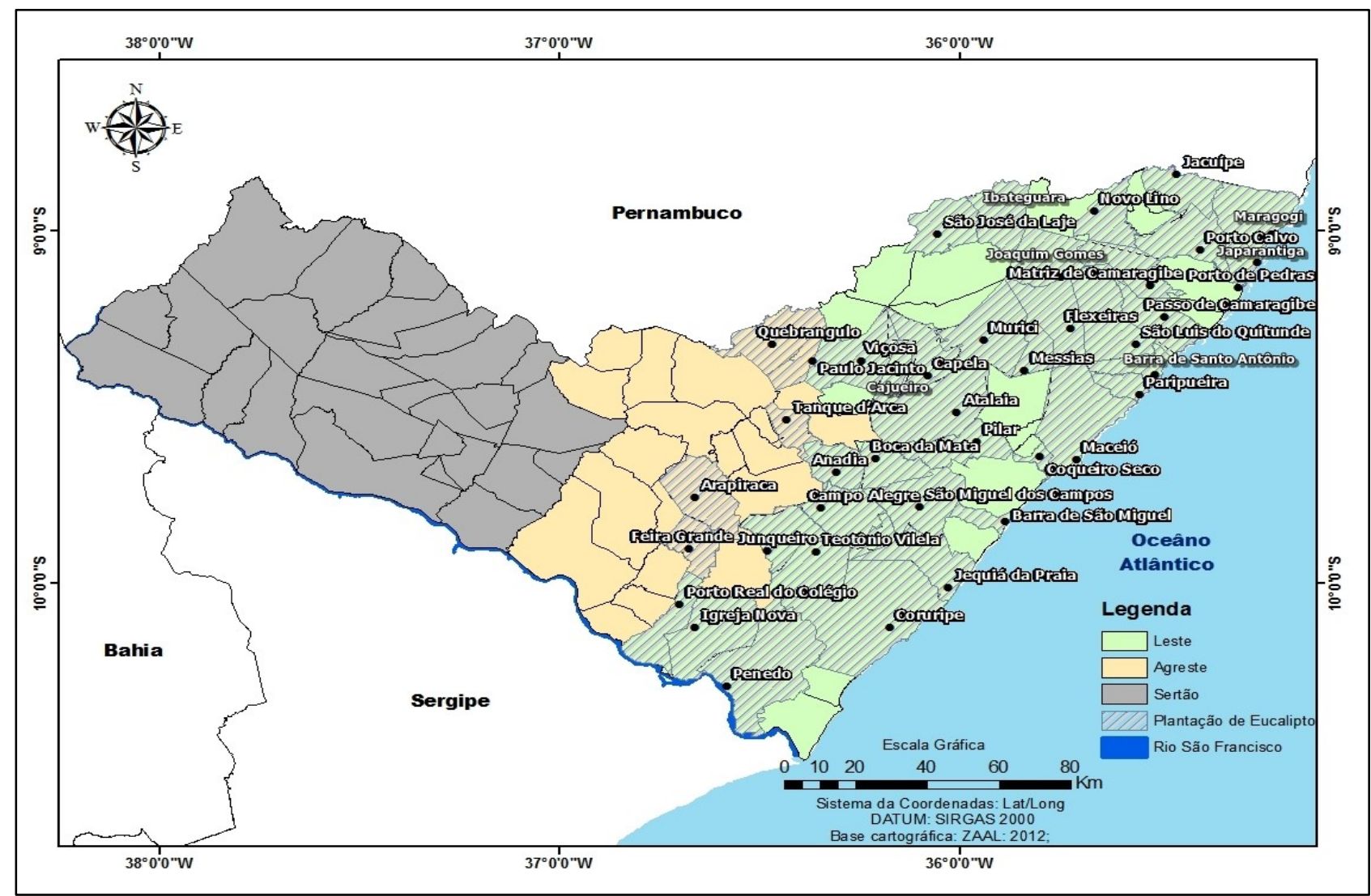

Figura 8 - Distribuição espacial do eucalipto em Alagoas (2018).

Fonte: Angeiras (2017); Trabalho de campo, 2018. Elaboração: própria.

\section{CONTRADIÇÕES À VISTA}

A euforia presente à narrativa do Estado com a expansão do eucalipto em Alagoas constitui um proposital embuste, que turva a análise das contradições imanentes. O incentivo à substituição, ainda que parcial, da cana-de-açúcar por árvores plantadas não representará alteração de grande monta na economia alagoana, pois está fincada em pilares, sobejamente, conhecidos, como a manutenção da estrutura fundiária concentrada, o monocultivo agrícola e a oferta de produtos não alimentares. Observemos os pormenores trágicos desse enredo. 
A expansão do eucalipto se materializa, predominantemente, na Mesorregião Leste, e em alguns municípios da Mesorregião Agreste, ocupando extensas áreas de solos, historicamente, utilizados para a cana-de-açúcar. Embora a narrativa oficial aponte para a possibilidade de coexistência do eucalipto com a produção de alimentos e a criação de animais, a realidade contraria tal assertiva. Por quê? Porque o plantio de árvores para o complexo de madeira-papel-celulose atende às aspirações do agronegócio, modelo de produção de mercadorias-commodity, guiado por taxas de lucro que, por sua vez, dependem da produtividade da madeira plantada. Portanto, em nenhum lugar desse país, as grandes propriedades com eucalipto compartilham os mesmos hectares para a produção de alimentos, de modo que a oferta destes últimos fica aos encargos das pequenas e médias propriedades. Os próprios documentos publicados pelo Estado não hesitam em afirmar, com certa euforia, a possibilidade da superfície cultivada com eucalipto ultrapassar gêneros alimentícios no estado. "A eucaliptocultura tendo em vista a sua fantástica cadeia produtiva, por certo, em um futuro muito próximo, virá a ocupar o segundo lugar entre as lavouras mais plantadas no estado, suplantando a mandioca, ficando somente atrás da cana de açúcar” (ALAGOAS, 2015b, p. 116).

Ou seja, ao mesmo tempo em que o Estado evoca a possibilidade de plantio de eucalipto consorciado à agricultura, celebra, contraditoriamente, a iminente superação da superfície cultivada com mandioca. Trata-se de uma indubitável manifestação de desprezo à soberania alimentar do estado.

No que se refere ao possível envolvimento da agricultura familiar na oferta de eucalipto, também é fácil encontrar incongruências entre a narrativa oficial e os imperativos da realidade. $\mathrm{O}$ custo por hectare de eucalipto é elevado, tornando difícil sua disseminação entre produtores familiares. Ademais, como relata o setor empresarial alagoano, em documento intitulado “Oportunidade dos eucaliptos em Alagoas", publicado em 2018, o cultivo desse gênero arbóreo demanda uma imobilização de investimentos na terra, além do acesso a créditos, que dificultam a participação de pequenos e médios produtores (SENAI, 2018). O mesmo documento salienta que esses pequenos e médios agricultores do estado já estão em dificuldades, pois muitos plantaram e forneceram cana-de-açúcar para as usinas, mas não receberam o pagamento devido. Assim, estão com as suas terras disponíveis, mas não possuem meios para investir (SENAI, 2018).

A baixa oferta de empregos é outro desdobramento inevitável do plantio de eucalipto. Não obstante as promessas de oferta de empregos na cadeia do complexo de madeira-papel-celulose, o ciclo vegetativo relativamente longo desse gênero arbóreo ( 5 a 7 anos), associado ao emprego de tecnologias poupadoras de força-de-trabalho - do plantio ao desbaste - oferta um número pequeno de empregos. 
As atividades nos monocultivos de árvores são as que menor quantidade de emprego geram, por unidade de área, principalmente em âmbito local e regional, pois são substituídas pelo uso cada vez mais intenso de máquinas e insumos químicos (fertilizantes e agrotóxicos) (LIMA et al., 2016, p. 31).

Os poucos empregos gerados ficam abaixo da economia da cana-de-açúcar. Esta, mesmo sob a reestruturação produtiva e baseando-se numa escandalosa superexploração da força-detrabalho, vale-se de um emprego sazonal de força-de-trabalho que, sequer, é visto nos imensos monocultivos de eucalipto. De acordo com dados do PNAD/IBGE (2013) apud DIEESE (2014), o percentual de trabalhadores assalariados, no Brasil, envolvidos no plantio de árvores para fins comerciais, não alcança $1 \%$ da totalidade dos empregados rurais. Um percentual bem abaixo das lavouras temporárias $(30,8 \%)$, da qual faz parte a cana-de-açúcar, e das lavouras permanentes $(16,4 \%)$.

A respeito do aproveitamento do eucalipto para ocupação preferencial de terrenos de topografia acidentada, é importante frisar que não condiz com a presença recente dessa árvore em terras alagoanas e com o modus operandi do agronegócio. Conforme dados do Senai (2018) a estimativa de plantio de eucalipto nas superfícies planas, em Alagoas, é da ordem de 57\% contra $43 \%$ de área de encostas. Tal distribuição percentual revela que, não obstante o Estado divulgue a presença do eucalipto em áreas declivosas, com fins substitutivos da cana-de-açúcar, ele tem se disseminado, majoritariamente, nas superfícies planas. A explicação para tal fenômeno repousa na lógica que preside o processo de acumulação do capital, a qual perscruta os meandros mais convenientes para obtenção do menor custo por hectare, a despeito das implicações sociais e ambientes decorrentes.

[...] para um modelo agrário/agrícola como o do capital latifundiário com suas extensas monoculturas é fundamental que os terrenos sejam planos ou, no máximo, suavemente ondulados [...], pois terrenos muito declivosos implicam em grandes custos de energia. E uma agricultura energívora, como essa do capital latifundiário monocultor, não pode prescindir de amplas áreas planas ou suavemente onduladas (PORTO-GONÇALVES, 2016, p. 74).

Em se tratando de questões sociais e ambientais, os episódios que conformam a história do cultivo comercial de eucaliptos no Brasil servem como importantes indicadores de quão grave é a situação. Conforme abordado alhures, a expansão do monocultivo de eucalipto no país tem deixado um rastro de contradições, em virtude da incompatibilidade entre o modus operandi do agronegócio e o respeito social e ambiental. A territorialização desse gênero arbóreo acontece em áreas de considerável disponibilidade hídrica, tendo em vista seu expressivo consumo de água, culminando, via de regra, em diminuição paulatina e/ou secamento de nascentes e mananciais. 
Cabe frisar que a presença de abundantes mananciais não é apenas um fator, mas sim uma condição estratégica e indispensável, tanto para o monocultivo arbóreo, quanto para o processamento industrial da celulose (PERPETUA; THOMAZ JUNIOR, 2016, p. 237).

Além disso, os monocultivos são mantidos com farto uso de agroquímicos cuja deriva, fatalmente, contamina os corpos d'agua e as lavouras de propriedades vizinhas. Em visita ao Assentamento de Reforma Agrária, Flor do Bosque, localizado no município de Messias, Zona da Mata Norte do estado, foi possível observar algumas destas consequências. O Assentamento decorreu da luta da Comissão Pastoral da Terra (CPT), iniciada em 1998, pela desapropriação das terras da antiga usina de cana-de-açúcar Bititinga. Atualmente, conta com mais de 40 famílias, que vivem em 35 lotes, produzindo uma diversidade de frutas, leguminosas, raízes e hortaliças. Desde 2006, parte dos camponeses assentados conquistou o selo de produtos orgânicos e, periodicamente, oferta seus produtos nas feiras próximas e, na capital, Maceió.

Ao longo de sua criação, o Assentamento Flor do Bosque sempre fez fronteira com o latifúndio monocultor de cana-de-açúcar. Porém, a partir de 2016, os assentados notaram que a gramínea estava cedendo passagem ao eucalipto. A paisagem, rapidamente, alterou-se, e os camponeses foram obrigados a conviver com um vizinho ainda mais indesejado.

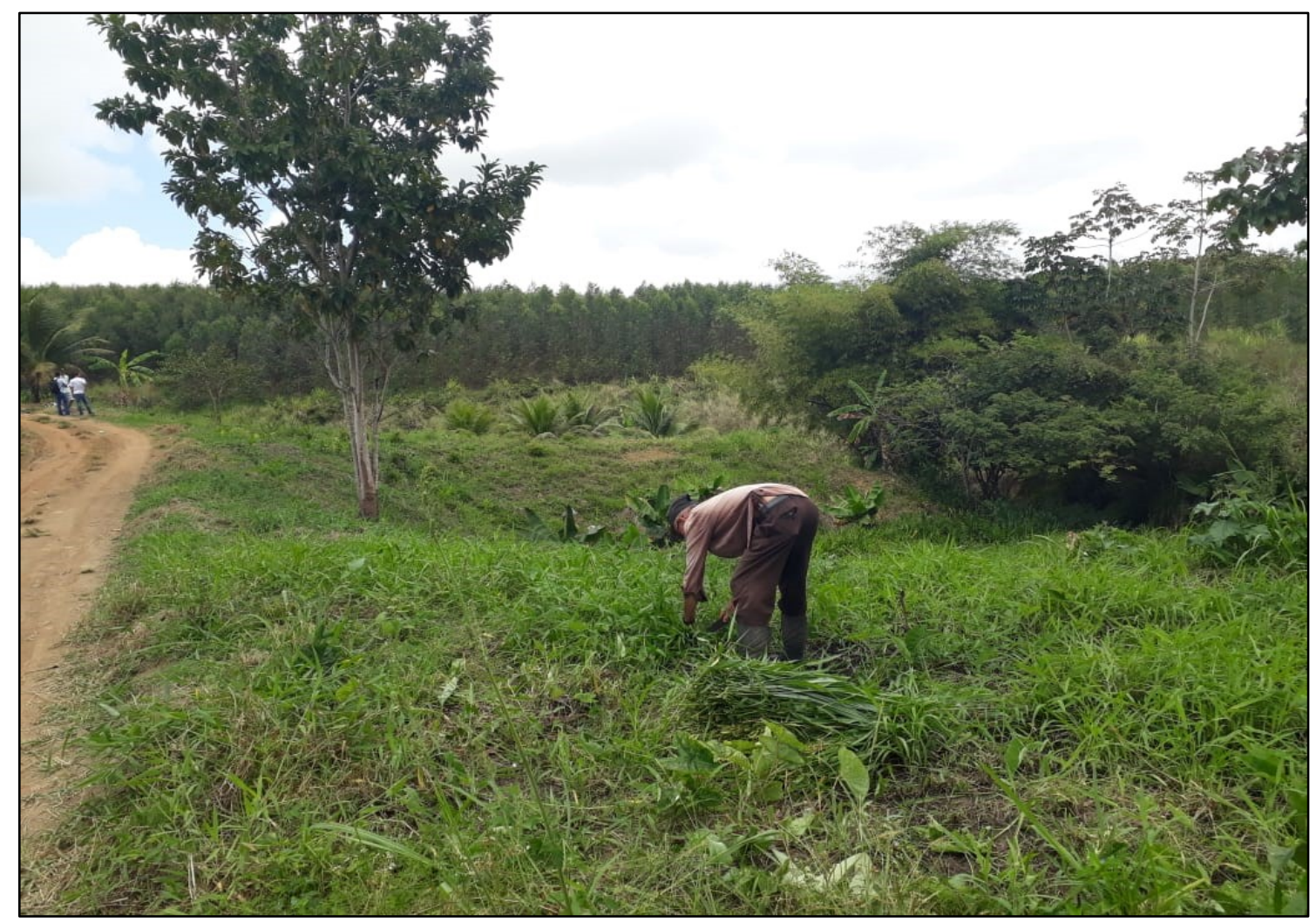

Figura 9 - Assentado trabalhando em seu lote e, ao fundo, plantação de eucalipto.

Fonte: Própria, setembro de 2018. 


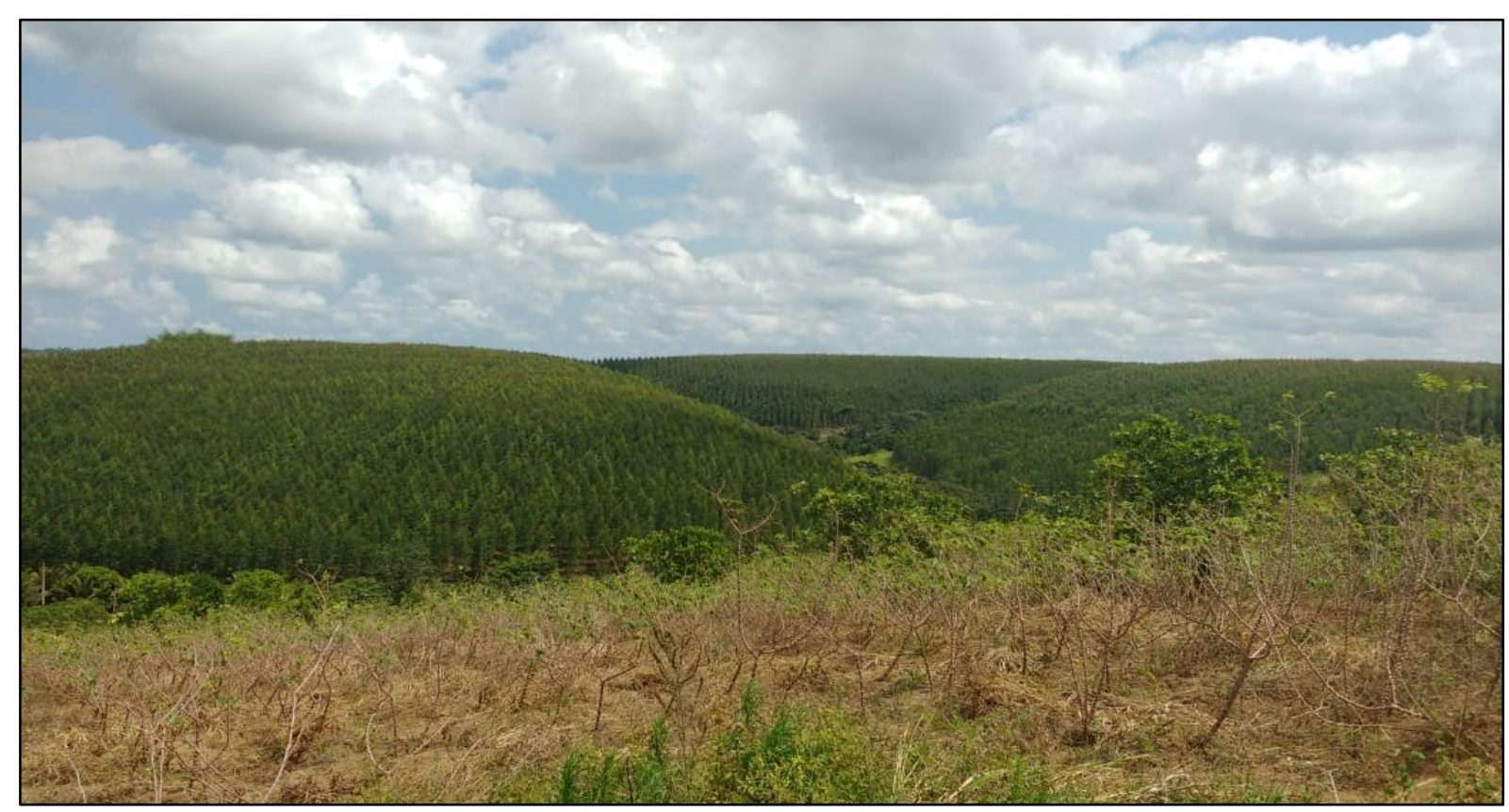

Figura 10 - Dimensão do cultivo de eucalipto na propriedade vizinha ao Assentamento Flor do Bosque.

Fonte: Própria, setembro de 2018.

Dos 35 lotes do assentamento, 13 fazem fronteira com o latifúndio do eucalipto. As árvores plantadas no latifúndio ainda são jovens, têm pouco mais de dois anos, mas já provocam danos à produção agrícola do Flor do Bosque. Segundo relato dos assentados, a nascente que fornece água às cacimbas dos lotes está situada no interior da grande propriedade, e desde a implantação dos hectares com eucalipto o volume hídrico ao alcance dos camponeses é menor.

Adicionalmente, foi relatada pelos assentados a contaminação das drenagens superficiais, que margeiam seus lotes. De acordo com aqueles, a pulverização aérea de agroquímicos sobre os eucaliptos ocorre quase diariamente. E a deriva resultante da pulverização tem tornado a convivência com o eucalipto bastante penosa. O trajeto dos aviões agrícolas deixa resíduos sobre suas fontes d'agua, plantações e, até mesmo, telhados das casas.

Um dia desse ele [o avião] passou que pensei que levaria minha casa. Derrubou um monte de coisa aí no telhado. Pensei que era chuva (Entrevistado 1, setembro de 2018).

Onde cai o negócio [agroquímico] nossas plantações ficam amarelas e não dão bem. Enxergue aquele pé de laranja ali, tá queimado (Entrevistado 2, setembro de 2018).

Os agricultores relatam que aumentou, substancialmente, o número de saúvas cortadeiras nas proximidades das suas plantações, em razão da presença do eucalipto, que constitui um atrativo à proliferação desses insetos. Também denunciam a ausência de pássaros e abelhas nos hectares desse gênero arbóreo.

Aí [na plantação de eucaliptos] só se vê aquelas saúvas. Tá cheio aí. Os pássaros e as abelhas, não sei o que é, mas não gostam não. Eles não vão para ali. Ficam aqui (Entrevistado 1, setembro de 2018). 
Além dos riscos à saúde e à disponibilidade hídrica, os assentados temem que a monocultura do eucalipto impute-lhes mais uma perda: a impossibilidade da continuidade da produção de orgânicos, em meio ao contexto de abundante pulverização aérea.

Ademais, os assentados também registraram uma notável diminuição no número de trabalhadores circulando dentro do latifúndio. Conforme os camponeses, antes, durante o plantio e colheita da cana-de-açúcar, era corriqueira a presença de funcionários em seus eitos. Desde a substituição da gramínea pelo eucalipto é raro avistar trabalhadores entre as árvores.

Em síntese, estes fatos revelam as primeiras contradições da presença do eucalipto no estado e demonstram a inexequibilidade da convivência entre a dinâmica voraz e predatória do agronegócio, que se territorializa mediante a monocultura e a destruição social e ambiental, e a dinâmica da produção camponesa, voltada à produção de alimentos e à construção do território como vida.

\section{CONSIDERAÇÕES FINAIS}

É expressiva a disseminação do cultivo de eucalipto em Alagoas, na última década. Saudado pelo Estado como uma alternativa à crise do setor sucroalcooleiro, o complexo de madeira-papel-celulose se territorializa, crescentemente, visando atender à reprodução ampliada do capital. Como parte de uma totalidade expansiva deste último, Alagoas tem se transformado em palco privilegiado para as imobilizações feitas pelas tradicionais oligarquias locais, consorciadas ou não, com grandes corporações empresariais, que vislumbram na disponibilidade fundiária, nas favorecidas condições edafoclimáticas e nos generosos incentivos do Estado a obtenção de preciosas vantagens comparativas.

A territorialização do eucalipto em Alagoas ocorre, predominantemente, na Mesorregião Leste do estado. Local que, por séculos, abriga o monocultivo da cana-de-açúcar e serve como base material para o poder oligárquico. A expansão das árvores plantadas, além de se situar em áreas de solos com boa qualidade e próximas a reservas hídricas, ocorre no momento em que a oferta de alimentos no estado torna-se ainda mais vulnerável. A produção e a superfície cultivada com feijão diminuíram em pouco mais de uma década.

Não obstante a campanha persuasiva empreendida pelo Estado, a fim de legitimar a substituição da cana-de-açúcar pelo eucalipto, sob a auréola do suposto respeito ao meio ambiente e da geração de empregos, os primeiros resultados encontrados apontam para impactos na oferta hídrica, no agravamento da contaminação de plantações e corpos d'agua com agroquímicos e na diminuição da dinâmica empregatícia. Os assentamentos de reforma agrária e as comunidades 
camponesas próximas ao latifúndio de árvores plantadas não estão imunes ao avanço do agronegócio, tendo sua dinâmica territorial alterada.

Compreende-se que esses desdobramentos, decorrentes da expansão do cultivo de eucaliptos, guardam íntima relação com o modus operandi do agronegócio, baseado no latifúndio, na monocultura, no uso generalizado de agroquímicos e numa oferta insignificante de empregos. Entretanto, a territorialização do eucalipto tende a agravar esses mecanismos perversos, fruto de sua própria dinâmica social e ambiental predatória. Em face do exposto, reiteramos que o deserto verde se alastra sob os auspícios do Estado, legando destruições.

\section{REFERÊNCIAS}

ALAGOAS. Atlas de Bioenergia de Alagoas 2015. Secretaria do Desenvolvimento Econômico e Turismo; Universidade Federal de Alagoas, 2015a. 81p.

ALAGOAS. Balanço Energético do Estado de Alagoas Ano Base 2014. Secretaria do Desenvolvimento Econômico e Turismo, 2015b. 182p.

ALAGOAS. Governador assina concessão de incentivos fiscais para instalação da empresa Duratex. Secretaria do Desenvolvimento Econômico e Turismo: Maceió, 2017. Disponível em: http://sedetur.al.gov.br/noticia/item/1952-governador-assina-concessao-de-incentivos-fiscais-parainstalacao-da-empresa-duratex Acesso em: 10 set. 2018.

ALMEIDA, R. A. Territorialização complexo eucalipto-celulose-papel em Mato Grosso do Sul. In: ENCONTRO NACIONAL DE GEOGRAFIA AGRÁRIA, 21., 2012, Uberlândia. Anais... Uberlândia, 2012.

ANGEIRAS, G. J. S. L. Mapear a implantação de florestas energéticas em Alagoas. Governo de Alagoas: Secretaria do Desenvolvimento Econômico e Turismo, 2017. 30p.

BINKOWAKI, P. Dinâmicas Socioambientais e disputas territoriais em torno dos empreendimentos florestais no Sul do Rio Grande do Sul. 2014. 264 f. Tese (Doutorado em Desenvolvimento Rural) - Faculdade de Ciências Econômicas, Universidade Federal do Rio Grande do Sul, Porto Alegre, 2014.

BRASIL. IBGE. Instituto Brasileiro de Geografia e Estatística. Produção da Extração Vegetal e da Silvicultura (PEVS) 2017. IBGE: Rio de Janeiro, 2017. Disponível em: https://www.ibge. gov.br/estatisticas-novoportal/economicas/agricultura-e-pecuaria/9105-producao-da-extracaovegetal-e-da-silvicultura.html?edicao $=22621 \& \mathrm{t}=$ sobre. Acesso em: 23 set. 2018.

BRASIL. CONAB. Companhia Nacional de Abastecimento. Série Histórica das Safras. CONAB: Brasília, 2019. Disponível em: <https://www.conab.gov.br/info-agro/safras/serie-historica-dassafras?start=30> Acesso em 28 jul. 2019.

BRITO, I. C. B. Monocultura de eucalipto, o desastre silencioso. In: ENCONTRO ANUAL DA ANPOCS, 41., 2017, Caxambu, Anais... Caxambu, 2007. 
CARVALHO, C. P. Análise da reestruturação produtiva da agroindústria sucroalcooleira alagoana. Maceió: EDUFAL, 2009. 113p.

DIEESE. Departamento Intersindical de Estatística e Estudos Socioeconômicos. O mercado de trabalho assalariado rural brasileiro. DIEESE, São Paulo, 2014. Disponível em: https://www. dieese.org.br/2014/estpesq74trabalhoRural.pdf Acesso em: 23 set. 2018.

ESKINAZI, B. G.; SOUZA, J. G. Especialização produtiva e homogeneização territorial: a monocultura de eucalipto no Vale do Paraíba Paulista e as transformações nas dinâmicas de produção. Revista Pegada, Presidente Prudente, v. 14, n. 2, p. 194-211, 2013.

GAZETA DE ALAGOAS. Duratex e Usina Caeté lançam projeto no estado: plantio será de 13.500 hectares em áreas arrendadas. Gazeta de Alagoas: Maceió, 2014. Disponível em: http://gazetaweb.globo.com/gazetadealagoas/noticia.php?c=257504 Acesso em: 10 set. 2018.

IBÁ. Cenários IBÁ: estatísticas da indústria brasileira de árvores. IBÁ: Brasília, 2018. Disponível em: <http://iba.org/images/shared/Cenarios/44_PDF_cenarios.pdf $>$ Acesso em: 30 jul. 2018.

IBÁ. Relatório Anual 2017. IBÁ: Brasília, 2017. Disponível em: http://iba.org/ images/shared/Biblioteca/IBA_RelatorioAnual2017.pdf Acesso em: 29 jul. de 2018.

KUDLAVICZ, M. Dinâmica agrária e a territorialização do complexo celulose/papel na microrregião de Três Lagoas/MS. 2011. 177 f. Dissertação (Mestrado em Geografia) - Programa de Pós-Graduação em Geografia, Universidade Federal do Mato Grosso do Sul, Campo Grande, 2011.

LESSA, G. L. Por um programa agrário para a esquerda alagoana. In: ALMEIDA, L. S.; LIMA, C. S.; OLIVEIRA, J. S. (Org.). Terra em Alagoas: temas e problemas. Maceió: EDUFAL, 2013. p. 309-324.

LIMA, A. R.; GIRARDI, E. P.; MANCIO, D.; NUNES, D. C. Impactos da monocultura do eucalipto sobre a estrutura agrária nas regiões norte e central do Espírito Santo. Revista NERA, Presidente Prudente, v. 19, n. 34, p. 12-36, 2016.

LIRA, F. J. Crise, privilégio e pobreza. Maceió: EDUFAL, 1997. 188p.

OLIVEIRA, A. U. Geografia Agrária: Perspectivas no início do século XXI. In: OLIVEIRA, A. U.; MARQUES, M. I. M. (Org.) O campo no século XXI: território de vida, de luta e de construção da justiça social. São Paulo: Editora Casa Amarela, 2004. p. 29-70.

OLIVEIRA, J. T.; SANTOS, J. L. O monocultivo de eucalipto como expressão capitalista da busca de territórios de consumo. In: RAMOS FILHO, E. S.; MITIDIERO JUNIOR, M. A.; SANTOS, L. R. S. Questão agrária e conflitos territoriais. São Paulo: Outras Expressões, 2016. p. 37-56.

PERPETUA, G. M.; THOMAZ JUNIOR, A. Revisitando o conceito de acumulação do capital: a pilhagem territorial promovida pela Veracel Celulose no Extremo Sul da Bahia. CampoTerritório, Edição Especial, p. 225-256, jun. 2016.

PORTO-GONÇALVES, C. W.; CUIN, D.; PANEZ, A.; SILVA, M. N.; SOTTO-MAIOR, M.; LEAL, L. Os cerrados e os fronts do agronegócio no Brasil. In: CANUTO, A.; LUZ, C. R. S.; ANDRADE, T. V. P. Conflitos no Campo - Brasil 2016. Goiânia: CPT Nacional, 2016. p. 74-87. 
SENAI. Oportunidades do eucalipto nos setores de serraria e painéis de madeira em Alagoas. Serviço Nacional de Aprendizagem Industrial/Departamento Regional de Alagoas: Maceió, 2018. 201p.

SILVA, C. E. M.; PORTO-GONÇALVES, C. W. Água, cerrado, eucalipto e gente. Cadernos do Ceas, Salvador, n. 222, p. 1-4, 2006.

SILVA, L. L. A política de reforma agrária em Alagoas entre 2003/13. In: ALMEIDA, L. S.; LIMA, C. S.; OLIVEIRA, J. S. (Org.) Terra em Alagoas: temas e problemas. Maceió: EDUFAL, 2013. p. 89-106.

VALORMERCADO. Duratex vai investir R\$ 1,1 bilhão e transformar Alagoas no maior polo moveleiro do Nordeste. VALORMERCADO: Maceió, 2017. Disponível em: http://valormercado. com.br/destaque/2017/10/duratex-vai-investir-r-11-bilhao-e-transformar-alagoas-no-maior-polomoveleiro-do-nordeste/ Acesso em: 10 set. 2018.

WALLIS, Victor. Para além do "capitalismo verde". In: GALVÃO, A.; AMORIM, E.; SOUZA, J. G.; GALASTRI, L. (Org.). Capitalismo: crises e resistências. São Paulo: Outras expressões, 2012. p. $21-48$.

Trabalho enviado em 30/07/2020

Trabalho aceito em $21 / 10 / 2020$ 